\title{
Relations Between Ice Motion Observed From Avhrr And Wind In The Greenland Sea
}

\section{Zhang, H; Gudmandsen, Preben}

Published in:

International Geoscience and Remote Sensing Symposium

Publication date:

1991

Document Version

Publisher's PDF, also known as Version of record

Link back to DTU Orbit

Citation (APA):

Zhang, H., \& Gudmandsen, P. (1991). Relations Between Ice Motion Observed From Avhrr And Wind In The Greenland Sea. In International Geoscience and Remote Sensing Symposium: Remote Sensing: Global Monitoring for Earth Management (Vol. Volume 2, pp. 815-818). IEEE.

\section{General rights}

Copyright and moral rights for the publications made accessible in the public portal are retained by the authors and/or other copyright owners and it is a condition of accessing publications that users recognise and abide by the legal requirements associated with these rights.

- Users may download and print one copy of any publication from the public portal for the purpose of private study or research.

- You may not further distribute the material or use it for any profit-making activity or commercial gain

- You may freely distribute the URL identifying the publication in the public portal

If you believe that this document breaches copyright please contact us providing details, and we will remove access to the work immediately and investigate your claim. 


\title{
RELATIONS BETWEEN ICE MOTION OBSERVED FROM AVHRR AND WIND IN THE GREENLAND SEA
}

\author{
H. Zhang and P. Gudmandsen \\ Remote Sensing Unit, Electromagnetics Institute, Technical University of Denmark \\ Building 348, DK-2800 Lyngby
}

\begin{abstract}
Using a computer-assisted ice feature tracking method ice motion in the Greenland Sea has been determined from AVHRR imageries acquired in the MIZEX-87 spring period, 9 March to 10 April. The ice motion data have been integrated with modelderived geostrophic winds and ice concentrations derived from passive microwave radiometer data in the same period. With this combined data set the ice motion and its correlation with wind and current in the Greenland Sea has been analyzed using a statistical method. The results have been compared with those obtained in studies based on drifting-buoy data of the much longer period of 1965-1984.
\end{abstract}

Keywords: Sea ice, Greenland Sea, geostrophic wind, AVHRR, SMMR.

\section{INTRODUCTION}

The response of sea ice motion to wind and current stress has been studied for the Arctic Ocean and the Greenland Sea in the period of 1965-84 by means of drifting buoy data [1, 2]. However, the spatial density of the buoy measurements is normally low which may lead to high sampling errors when applied to the statistics of ice motion. This problem may be overcome by means of satellite imagery. By tracking ice features from the Advanced Very-High Resolution Radiometer (AVHRR) images via a computer-assisted ice feature tracking method [3], ice velocity data with much higher spatial density have been obtained for the period of MIZEX-87, late February to May 1987. Combining the ice movement data with wind data from the same period, the relationship between ice motion and the geostrophic wind in the Greenland Sea has been investigated, especially for the one-month period of 9 March to 10 April 1987. In addition, ice concentrations were derived from data acquired from the Scanning Multichannel Microwave Radiometer (SMMR).

In this paper, the data sets of ice velocity, ice concentration and wind for the one-month period are briefly described. Ice motion data are presented and the elementary momentum-balance equation relating the three variables of ice motion, wind and current, are introduced. On this basis the correlation between ice drift and wind and current is derived. The results are compared with those derived from buoy data.

\section{DATA SET}

The ice velocity data are obtained from AVHRR images by using a computer-assisted method. In order to obtain a large number of data cloud-free as well as partly cloud-free images of the Greenland Sea have been utilized. Also, images received at different times of a day are used. In this way, a total of 24 images have been obtained for the period 9 March to 10 April constituting 21 pairs from which ice velocities of 2129 ice feature are measured.

The ice concentration data are derived from SMMR using multichannel algorithms [4]. They are stored as a time series with one data set for every second day in the one-month period. The pixel size is $30 \times 30 \mathrm{~km}^{2}$ and the spacing between pixels is interpolated to $15 \mathrm{~km}$.

The geostrophic wind data used in this work are derived from the DMI-LAM (Danish Meteorological Institute Limited Area Model) [5]. There is a set of wind data available at 13:00 GMT every day from 15 February to 15 May 1987 with a grid spacing of about $100 \mathrm{~km}$.

These three types of data are combined to a data set in the way that for each measured ice feature, the values of ice concentration and wind at the same position and time are retrieved from 
the database. Due to the fact that the ice velocity, concentration and the wind data are derived from different data sources with different spatial and time resolution, temporal and spatial interpolations are carried out .

\section{ICE MOTION IN THE GREENLAND SEA}

Table 1 lists the mean and variance of ice velocity calculated from 2129 measurements in the Greenland Sea for the period. The u-component and the v-component in the table are directed from west to east and from north to the south, respectively. For comparison, the same quantities, obtained from buoy data for the much longer period of 1965-1984 [2], are also listed.

It is seen that ice moves with a large mean velocity (about 16 $\mathrm{cm} / \mathrm{s}$ ) which is very close to that arrived at from the multiyear buoy data. From the histogram of measured ice velocity [6], it is found that the velocities range from 0 to $80 \mathrm{~cm} / \mathrm{sec}$ with $80 \%$ of the observations within $10 \mathrm{~cm} / \mathrm{sec}$ to $30 \mathrm{~cm} / \mathrm{sec}$. The ice motion fluctuations are characterized by the standard deviation $\sigma_{\mathrm{u}}$ of $11.4 \mathrm{~cm} / \mathrm{s}$ which is of the same order as the mean velocity. The larger standard deviation of $18.6 \mathrm{~cm} / \mathrm{sec}$ for the longer period may be explained by seasonal and annually variations of ice motion. In particular, it is important that the buoy data also include data for summer months with low ice concentrations.

Table 1 Statistics of the sea ice motion and the geostrophic wind

\begin{tabular}{|c|c|c|}
\hline Variables & $\begin{array}{c}\text { AVHRR data } \\
\text { (9 Mar,-10 Apr. 1987) } \\
\end{array}$ & $\begin{array}{l}\text { Buoy data } \\
(1965-1984)\end{array}$ \\
\hline$N$ & 2129 & 1535 \\
\hline$<u>$ & $-2.5 \mathrm{~cm} / \mathrm{s}$ & $-2.4 \mathrm{~cm} / \mathrm{s}$ \\
\hline$<v>$ & $-15.3 \mathrm{~cm} / \mathrm{s}$ & $-14.3 \mathrm{~cm} / \mathrm{s}$ \\
\hline$\left.<\mathrm{G}^{(\mathrm{x})}\right\rangle$ & $-7.1 \mathrm{~m} / \mathrm{s}$ & $-0.8 \mathrm{~m} / \mathrm{s}$ \\
\hline$\langle\mathrm{G}(\mathrm{y})\rangle$ & $-4.5 \mathrm{~m} / \mathrm{s}$ & $-2.0 \mathrm{~m} / \mathrm{s}$ \\
\hline$\sigma_{\mathbf{u}}$ & $11.4 \mathrm{~cm} / \mathrm{s}$ & $18.6 \mathrm{~cm} / \mathrm{s}$ \\
\hline$|\mathbf{A}|$ & $0.124 \times 10^{-2}$ & $1.21 \times 10^{-2}$ \\
\hline$\theta$ & $43^{\circ}$ & $-3^{0}$ \\
\hline$\rho^{2}$ & 0.075 & 0.23 \\
\hline$\rho \sigma_{\mathrm{u}}$ & $3.1 \mathrm{~cm} / \mathrm{s}$ & $8.9 \mathrm{~cm} / \mathrm{s}$ \\
\hline$\sigma_{\mathrm{E}}$ & $11.0 \mathrm{~cm} / \mathrm{s}$ & $16.4 \mathrm{~cm} / \mathrm{s}$ \\
\hline$\left\langle\mathrm{c}(\mathrm{x})_{\rangle}\right.$ & $-2.2 \mathrm{~cm} / \mathrm{s}$ & $-1.3 \mathrm{~cm} / \mathrm{s}$ \\
\hline$<\mathrm{c}(\mathrm{y})>$ & $-14.3 \mathrm{~cm} / \mathrm{s}$ & $-11.9 \mathrm{~cm} / \mathrm{s}$ \\
\hline
\end{tabular}

In order to show the spatial variations of ice motion and its correlations with the geostrophic wind, the Greenland Sea region is divided into a number of boxes with a size of $111 \times 111 \mathrm{~km}^{2}$. The number of measurement samples is different from box to box and so is the number of the sampled days. It should be noted that the sampling statistics of ice velocity and wind in each box will be calculated from the samples which fall within a box. In order to obtain representative results, only boxes with more than 20 measurements are considered.

The vectors of sample mean ice velocity derived from each box is shown in Fig.1. It is seen that the mean ice velocity vectors are predominantly southward, roughly parallel to the coast of the Greenland and the bathymetry, turning south-to-westward at $75^{\circ} \mathrm{N}$ with the shelf break. Also, the mean southward component increased from the near coast areas to the continental slope. The mean ice velocity is smallest ( 3 to $12 \mathrm{~cm} / \mathrm{s}$ ) in the northern Fram Strait, increasing towards the south (up to 26 $\mathrm{cm} / \mathrm{s}$ ) with the largest increase of velocity observed in the Fram Strait. Unfortunately, because of the limited spatial resolution of the AVHRR data and the highly broken ice pack, very few measurements have been made in the marginal ice zone. Also, only very few measurements have been made in the areas close to the coast which are covered mainly by fast ice with no or very small movements in the period.

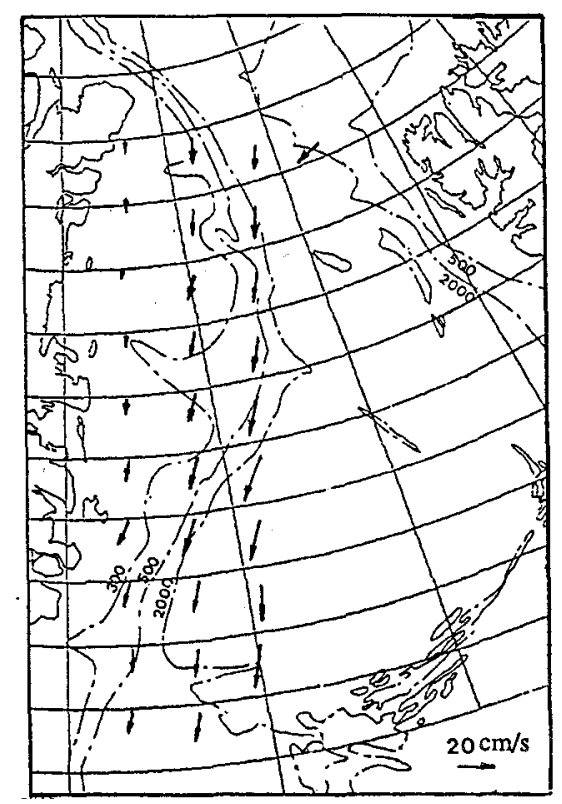

Fig.1: Sample means of ice velocity in each box

\section{CORELATION OF ICE MOTION WITH WIND}

Following Thorndike and Colony [1], we use a linear equation to examine the correlation of ice motion to wind in the Greenland Sea. The equation which stems from a momentum balance equation of ice motion under assumption of free drift and wind speeds larger than $2.5 \mathrm{~m} / \mathrm{s}$ reads:

$$
\mathrm{U}=\mathrm{A} * \mathrm{G}+<\mathrm{c}>+\mathrm{E}
$$

where $U$ is the ice velocity, $G$ the geostrophic wind, $\langle c\rangle$ is the geostrophic current which is assumed to be constant and $\mathrm{E}$ is a 
residual including contributions of measurement errors, timevarying current and other effects neither constant nor linear functions of the wind. The term $A=|A| e^{i \theta}$ is a wind factor where the turning angle $\theta$ is measured clockwise positive from $\mathrm{U}$ to $\mathrm{G}$. B can be obtained from a complex regression process [2] using a set of $U$ and $G$ values. Another parameter, $\rho^{2}$, the squared correlation coefficient, is introduced to describe the fraction of the variance of ice velocity which is explained by the geostrophic wind.

The statistical quantities of the correlation between ice and wind in the Greenland Sea based on (1) have been calculated and are presented in Table 1 . The results from the study based on multiyear buoy data are also included for comparison.

The squared correlation coefficient $\rho^{2}=0.075$ implies that only $7.5 \%$ of the variance of ice motion fluctuations are accounted for by the wind assuming a constant current $<c>$. This shows that the fluctuations of the ice motion in the Greenland Sea are largely dominated by a non-wind driven force, although the mean value of wind driving velocity fluctuation, $\rho \sigma_{u}$, is 3.1 $\mathrm{cm} / \mathrm{s}$, which is not negligible. The high residual variation $\sigma_{\mathrm{E}}$ indicates that variable currents, for example, are important for the ice motion in the Greenland Sea.

$\mathrm{B}=0.124 \times 10^{-2} \mathrm{e}^{\mathrm{i} 43^{\circ}}$ implies that in the absence of a current, sea ice in the Greenland Sea moves in response to the wind at a velocity of 0.00124 times the wind speed in the direction of $43^{\circ}$ to the left of the wind, i.e. eastwards. This suggests a very small correlation between ice motion and geostrophic wind. In contrast, the multiyear buoy data show a ten times larger response to the wind directed $3^{\circ}$ to the right of wind [2]. This large difference may be explained by the different time scales of the two data sets. Also, a large part of the buoy data were obtained from summer periods, while, the one-month data are measured only in early spring when the ice concentrations in average are much larger.

Fig. 3 - 5 show the spatial variation of the squared correlation $\rho^{2},|\mathbf{B}|$ and the turning angle $\theta$ in different regions, selected as boxes in the Greenland Sea. The most northwestern box is empty due to the absence of wind data in that box. It is seen that in the entire Greenland Sea, values of $|\mathbf{B}|$ are very small especially in the northwestern part with a minimum of $|\mathbf{B}|=$ 0.0003 , and large turning angles, with variations from $-144^{\circ}$ to $131^{\circ}$, suggesting that there is no correlation between the ice motion and geostrophic wind. In contrast, $|\mathbf{B}|$ becomes much larger in the southern part of the Greenland Sea with a maximum of 0.0104 while the turning angles becomes smaller. $\rho^{2}$ attains to $69.8 \%$ near the ice boundary or about 35 times the minimum value observed in the northwestern areas. This

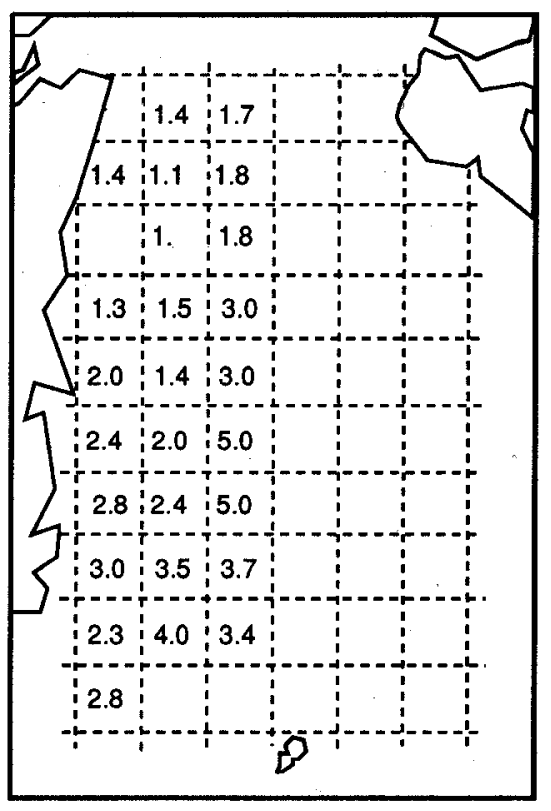

Fig.2: $|\mathrm{B}| \mathrm{x} 1000$ in each box.

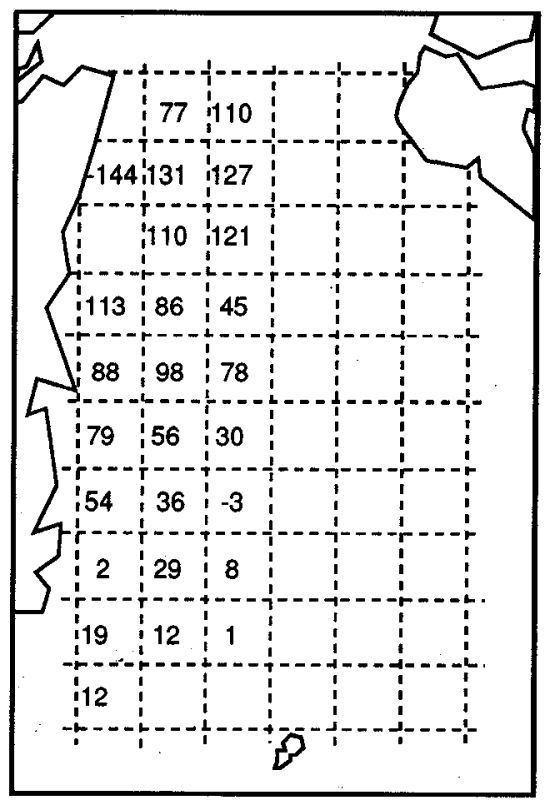

Fig.3: Turning angle $\theta$ (degree) in each box

indicates that the fluctuation in the geostrophic wind determines a large part of the ice drift variations in the marginal ice zone. But, since $\rho^{2}$ is smaller than $50 \%$ in most of the boxes it is concluded that currents dominate both the sea ice velocity and its variation in most parts of the Greenland Sea in the period in question .

The spatial variations of $B$ and $\rho^{2}$ suggest an increasing influence of the wind-driving forces when approaching the ice boundary. This may due to the increased divergence and re- 


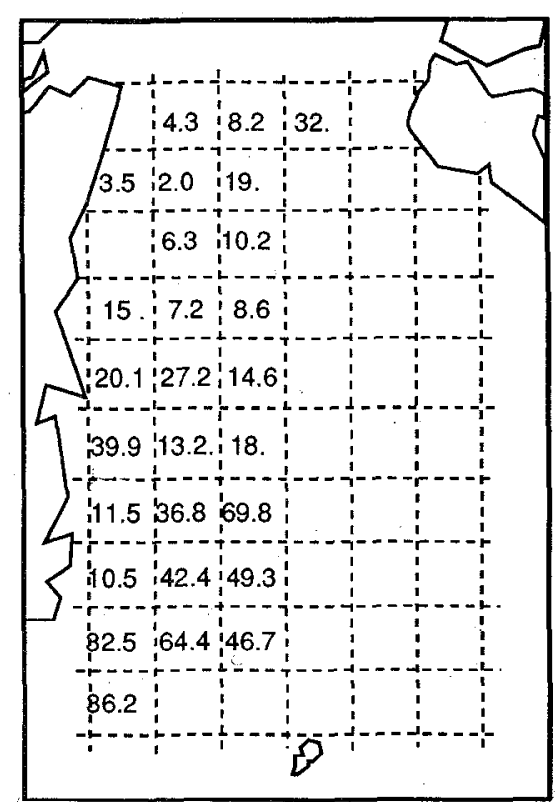

Fig.4: $\rho^{2} \times 100$ in each box.

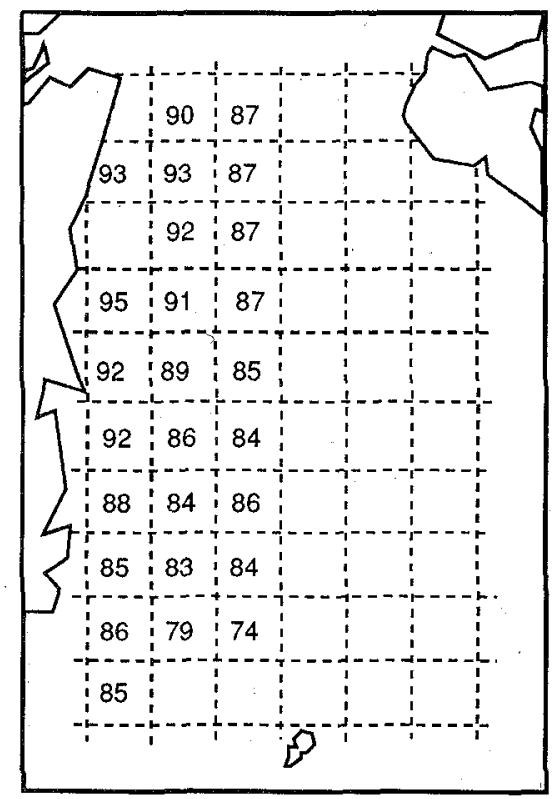

Fig.5: Sample mean ice concentrationin each box

duced ice concentration and the resulting reduced internal stress from the near-coast to the ice boundary and from the northern to the southern areas. The sample means of ice concentration in each box are shown in Fig.5. It is seen that the means of ice concentration are higher than $80 \%$ in most of the boxes except in the areas near the ice boundary. In the northwestern areas the ice concentration is over $90 \%$, while in the southeastern areas they are of the order of $70 \%$. From the AVHRR images it is also found that ice in the northwestern region is mainly shore fast ice most likely close to $100 \%$ concentration. It is suggested that the wind-driven motion is very sensitive to variations in ice concentration, at least when the ice concentration is higher than a certain value - $85 \%$, for instance - and that the free-drift assumption and therefore the approximate linear relationship between ice motion and geostrophic wind assumed for the derivation of (1) may not hold in such areas.

\section{CONCLUSIONS}

A data set of ice velocity, wind and ice concentration for a period of MIZEX-87, March 9 to April 10, 1987, has been obtained from satellite and model data in the Greenland Sea. It is observed that sea ice in this period moved with a fairly high mean velocity, mainly southward and roughly parallel to the coast of Greenland and the isobaths. Of the large range of speed from 0 to $80 \mathrm{~cm} / \mathrm{s}, 80 \%$ of the measured ice velocities are within $10 \mathrm{~cm} / \mathrm{s}$ to $30 \mathrm{~cm} / \mathrm{s}$. The statistical analyses of wind and sea ice motion indicate that, unlike in the central Arctic Ocean, both the mean and the fluctuating ice motion were dominated by the surface current while the surface geostrophic wind was of secondary importance The response of ice motion to the wind varied from place to place with a relative higher correlation in the south and in the marginal ice zone, probably due to the lower ice concentrations in these areas. In fact, the effect of the wind seems to be dependent upon the ice concentration with negligible effect when the concentration is larger than $85 \%$. In order to arrive at a more complete understanding of sea ice motion and its correlation with wind, data covering all seasons and a number of years should be studied. A data set for another winter period, December 1988 - January 1989, has shown the same trend as described above but with lower mean velocities in general and with little influence of the wind [7]. These data sets of ice velocity, geostrophic wind and ice concentration are available in digital format to support further studies.

\section{REFERENCES}

[1] Thorndike, A. and R. Colony, "Sea ice motion in response to geostropic wind", J. Geophys. Res., 87(C38), 1982, pp. $5845-5852$.

[2] Moritz, R. E., "The ice budget of the Greenland Sea" Technical Report, APL-UW, University of Washington, TR8812, 1988, $117 \mathrm{pp}$.

[3] Zhang, H., L.T. Pedersen and P. Gudmandsen, "Ice motion in the Greenland Sea determined from satellite remote sensing data", Proc..EARSeL Symp., 1989, pp.137-143.

[4] Pedersen, L. T., "Retrieval of sea ice concentration by means of microwave radiometry", Ph.D Thesis, LD 81, Electromagnetics Institute, 1991, $148 \mathrm{pp}$.

[5] Isaksen, L., "The weather in the Greenland Sea area during MIZEX-87", Report of the Greenland Sea Project, No.10, 1988,177 pp.

[6] Zhang, H., "Ice motion and its correlation to wind in the Greenland Sea", Report of the Greenland Sea Project, No. $39, .1990,49 \mathrm{pp}$.

[7] Gudmandsem.P. and H. Zhang, "AVHRR data from the Greenland Sea, 16 December 1988 - 28 January 1989 , Report of the Greenland Sea Project, No. 38, 1991, 64 pp. 